\title{
Evaluation of preoperative computed tomography angiography in association with conventional angiography versus computed tomography angiography only, in the endovascular treatment of aortic diseases*
}

\author{
Avaliação da realização pré-operatória da angiotomografia associada a angiografia convencional versus \\ angiotomografia apenas no tratamento endovascular das doenças da aorta \\ Patrick Bastos Metzger ${ }^{1}$, Eduardo Rafael Novero ${ }^{2}$, Fabio Henrique Rossi ${ }^{3}$, Samuel Martins Moreira ${ }^{4}$, \\ Frederico Augusto Linhares ${ }^{5}$, Bruno Lorenção de Almeida ${ }^{6}$, Heraldo Antônio Barbato ${ }^{7}$, Nilo Mitsuru \\ Izukawa $^{8}$, Antonio Massamitsu Kambara ${ }^{9}$
}

\begin{abstract}
Objective: To evaluate the association of conventional angiography (AG) with computed tomography angiography (CTA) as compared with CTA only, preoperatively, in the treatment of aortic diseases. Materials and Methods: Retrospective study involving patients submitted to endovascular treatment of aortic diseases, in the period from January 2009 to July 2010, with use of preoperative CTA + conventional AG or CTA only. The patients were divided into two groups, namely: G1 - thoracic aortic diseases; and G2 - abdominal aortic diseases. G1 was subdivided into $1 \mathrm{~A}$ (preoperative AG + CTA) and $1 B$ (preoperative CTA). G2 was subdivided into $2 \mathrm{C}(\mathrm{CTA}+\mathrm{AG})$ and $2 \mathrm{D}$ (CTA only). Results: The authors evaluated 156 patients. In subgroups $1 \mathrm{~A}$ and $1 \mathrm{~B}$, the rate of technical success was, respectively, $100 \%$ and $94.7 \%(p=1.0)$; and the rate of therapeutic success was, respectively, $81 \%$ and $58 \%(p=0.13)$. A higher number of complications were observed in subgroup 1B $(p=0.057)$. The accuracy in the calculation of the prosthesis was higher in subgroup $1 \mathrm{~A}(p=$ 0.065). In their turn, the rate of technical success in subgroups $2 \mathrm{C}$ and $2 \mathrm{D}$ was, respectively, $92.3 \%$ and $98.6 \%$ ( $p=$ 0.17). The rate of therapeutic success was $73 \%$ and $98.6 \%(p=0.79)$. Conclusion: Preoperative conventional AG should be reserved for cases where CTA cannot provide all the information in the planning of a therapeutic intervention. Keywords: Aneurysm; Vascular prosthesis; Angiography.
\end{abstract}

Resumo Objetivo: Avaliar a associação entre angiografia (AG) e angiotomografia (ATG) pré-intervenção, comparada apenas à ATG, no tratamento de doenças aórticas. Materiais e Métodos: Estudo retrospectivo, envolvendo pacientes submetidos a tratamento endovascular de doenças aórticas, no período de janeiro de 2009 a julho de 2010, com o uso de AG + ATG pré-operatória ou apenas ATG. Os pacientes foram divididos em: G1 - doenças da aorta torácica; G2 - doenças da aorta abdominal. O G1 foi subdividido em 1A (submetidos a AG + ATG pré-operatória) e 1B (ATG pré-operatória). 0 G2 foi subdividido em 2C (ATG + AG) e 2D (ATG). Resultados: Foram analisados 156 pacientes. Nos subgrupos 1A e 1B, o sucesso técnico foi $100 \%$ e $94,7 \%(p=1,0)$ e o sucesso terapêutico de $81 \%$ e $58 \%(p=0,13)$. Foram observadas mais complicações no subgrupo 1B $(p=0,057)$. A precisão do cálculo da prótese foi maior no subgrupo $1 \mathrm{~A}(p=$ 0,065). Por sua vez, nos subgrupos 2 C e 2D, o sucesso técnico foi 92,3\% e 98,6\% ( $p=0,17)$ e o sucesso terapêutico foi $73 \%$ e 98,6\% ( $p=0,79)$. Conclusão: A AG diagnóstica deve ser reservada aos casos em que a ATG não é capaz de fornecer todas as informações necessárias no planejamento de uma intervenção terapêutica.

Unitermos: Aneurisma; Prótese vascular; Angiografia.

Metzger PB, Novero ER, Rossi FH, Moreira SM, Linhares FA, Almeida BL, Barbato HA, Izukawa NM, Kambara AM. Evaluation of preoperative computed tomography angiography in association with conventional angiography versus computed tomography angiography only, in the endovascular treatment of aortic diseases. Radiol Bras. 2013 Set/Out;46(5):265-272.

* Study developed at Instituto Dante Pazzanese de Cardiologia, São Paulo, SP, Brazil.

1. Vascular and Endovascular Surgeon, Fellow PhD degree, Physician Assistant at Unit of Interventional Radiology, Instituto Dante Pazzanese de Cardiologia, São Paulo, SP, Brazil.

2. MD, Interventional Cardiologist, Foreign Trainee at Centro de Intervenções Endovasculares (CIEV), Instituto Dante Pazzanese de Cardiologia, São Paulo, SP, Brazil, Hemodynamicist in Santa Fé, Argentina.

3. PhD, MD, Physician Assistant at Vascular Surgery Division, Instituto Dante Pazzanese de Cardiologia, São Paulo, SP, Brazil.
4. Vascular and Endovascular Surgeon, Physician Assistant at Unit of Intervetional Radiology, Instituto Dante Pazzanese de Cardiologia, São Paulo, SP, Brazil.

5. MD, Vascular Surgeon, Trainee at Centro de Intervenções Endovasculares (CIEV), Instituto Dante Pazzanese de Cardiologia, São Paulo, SP, Brazil.

6. Vascular and Endovascular Surgeon, Fellow PhD degree Physician Assistant at Unit of Interventional Radiology, Instituto Dante Pazzanese de Cardiologia, São Paulo, SP, Brazil.

7. Vascular and Endovascular Surgeon, Angioradiologist, Physician Assistant at Vascular Surgery Division, Instituto Dante Pazzanese de Cardiologia, São Paulo, SP, Brazil.
8. PhD, Head of Vascular Surgery Division, Instituto Dante Pazzanese de Cardiologia, São Paulo, SP, Brazil.

9. PhD, Titular Member of Colégio Brasileiro de Radiologia e Diagnóstico por Imagem (CBR), Head of Radiology Division, Instituto Dante Pazzanese de Cardiologia, São Paulo, SP, Brazil.

Mailing Address: Dr. Patrick Bastos Metzger. Centro de Intervenções Endovasculares (CIEV). Avenida Doutor Dante Pazzanese, 500, Vila Mariana. São Paulo, SP, Brazil, 04012-909. E-mail: patrickvascular@gmail.com. 2013 


\section{INTRODUCTION}

The ideal imaging method in the preparation for endovascular aortic repair must allow the assessment of the vessel diameter, of the aortic wall and iliac arteries characteristics, as well as the evaluation of the proximal and distal aortic necks in the regions involved by the disease to be treated.

Until recently, since the development of the technique by Seldinger et al. in 1953 , conventional angiography (AG) has been considered as the standard method for the diagnosis of aortic diseases. The angiographic study corresponds to the injection of a contrast agent into the vascular system to be visualized with the utilization of $\mathrm{x}$ rays ${ }^{(\mathbf{1})}$. Such method can map the entire aorta, providing accurate information on its branches, aortic ostium, reentry, rupture zones and ulcerations. The major benefit from aortography is determining the relationship between the aneurysm or aortic flap and the vessels of the aortic arch, besides allowing the diagnosis of aortic insufficiency and presence of cephalic alteration of the coronary ostium. AG is indicated for patients above the age of 40 , with the objective of diagnosing concomitant coronary diseases. Such imaging method allows the evaluation of the vessel lumen, but does not evaluate its walls as well as the presence of mural thrombi, providing a suggestive diagnosis ${ }^{(2)}$. AG only is not sufficient to provide all the information required to enable endovascular treatment of aortic disease ${ }^{(3-6)}$.

Currently, multislice CT angiography is the method of choice for the diagnosis and topographic evaluation of the aorta, since it is available in many centers and presents high sensitivity and specificity, besides being rapidly and less invasively performed $^{(7-9)}$. Multislice CT angiography can provide information on structures adjacent to the aorta, ventricular wall thickness, presence of coronary calcification, pericardial effusion, aortic dimensions, disease extent, presence of thrombi, aortic wall characteristics, delamination, hematomas, ulcerations, main branching and occlu$\operatorname{sion}^{(2)}$.

In the authors' institution, all the patients eligible for endovascular treatment are preoperatively assessed with CT an- giography and, optionally, AG as a complementary tool.

The present study was aimed at evaluating the association between AG and CT angiography preoperatively as compared with CT angiography only, in the treatment of aortic diseases, approaching the following variables: technical success, therapeutic success, complications, correct endoprosthesis calculation, and mortality.

\section{MATERIALS AND METHODS}

\section{Study design}

A retrospective, longitudinal, observational and comparative study was designed and developed in a reference center for cardiovascular diseases in São Paulo, SP, Brazil, in the period from January 2009 to July 2010. The study sample comprised 156 patients submitted to endovascular repair of abdominal and thoracic aortic diseases. Such a population was divided into two groups, namely: group $1(\mathrm{G} 1)$ - thoracic aortic interventions; group 2 (G2) - abdominal aortic interventions. The G1 was subdivided into 1A (patients submitted to preoperative aortography and CT angiography), and $1 \mathrm{~B}$ (patients submitted to $\mathrm{CT}$ angiography only). The $\mathrm{G} 2$ was subdivided into $2 \mathrm{C}$ and $2 \mathrm{D}$, corresponding to patients preoperatively submitted to CT angiography + AG, and to CT angiography only, respectively (Figure 1).

\section{Inclusion and exclusion criteria}

The present study included male and female, symptomatic and asymptomatic patients with indication for endovascular treatment for the following aortic diseases $^{(\mathbf{4 , 1 0 - 1 2})}$ :

1 - Abdominal aortic aneurysm with $>55 \mathrm{~mm}$ in diameter in male individuals, and $>50 \mathrm{~mm}$ in female individuals.

2 - Type I or type II leakage in previously treated patients.

3 - Thoracic aortic aneurysm with $>55$ $\mathrm{mm}$ in diameter.

4 - Chronic Stanford type B aortic dissection with aneurysmal dilatation $>55$ $\mathrm{mm}$, or type I/type III leakage repair.

5 - Thoracic aortic pseudoaneurysm.

6 - Penetrating thoracic aortic ulcer with $>2 \mathrm{~cm}$ in diameter and $1 \mathrm{~cm}$ in depth.

Patients with the following conditions were excluded: proximal neck length $<15$ $\mathrm{mm}$, presence of thrombus or calcification $>50 \%$ of the neck diameter, proximal neck angle $>65^{\circ}$, aortoiliac bifurcation angle $>90^{\circ}$, external iliac arteries diameter $<7$ $\mathrm{mm}$, creatinine serum levels $>2.0 \mathrm{mg} / \mathrm{dl}$ or creatinine clearance $<30 \mathrm{ml} / \mathrm{min}$.

The patients who met the inclusion and exclusion criteria were consecutively referred for endovascular treatment. The cardiological and/or anesthetic risks were not taken into consideration for inclusion or exclusion of patients. In all of the cases, the diagnosis and the therapeutic schedule were based on CT angiography, as preoperative conventional $\mathrm{AG}$ was an optional diagnostic method. Multiplanar and 3D reconstructions of all the CT angiography images were made with the AID of the Osirix ${ }^{\circledR}$ software, allowing the obtention of diameters, angles and length of proximal aortic necks, aneurysms and aortoiliac bifurcations (Figures 2, 3, 4 and 5).

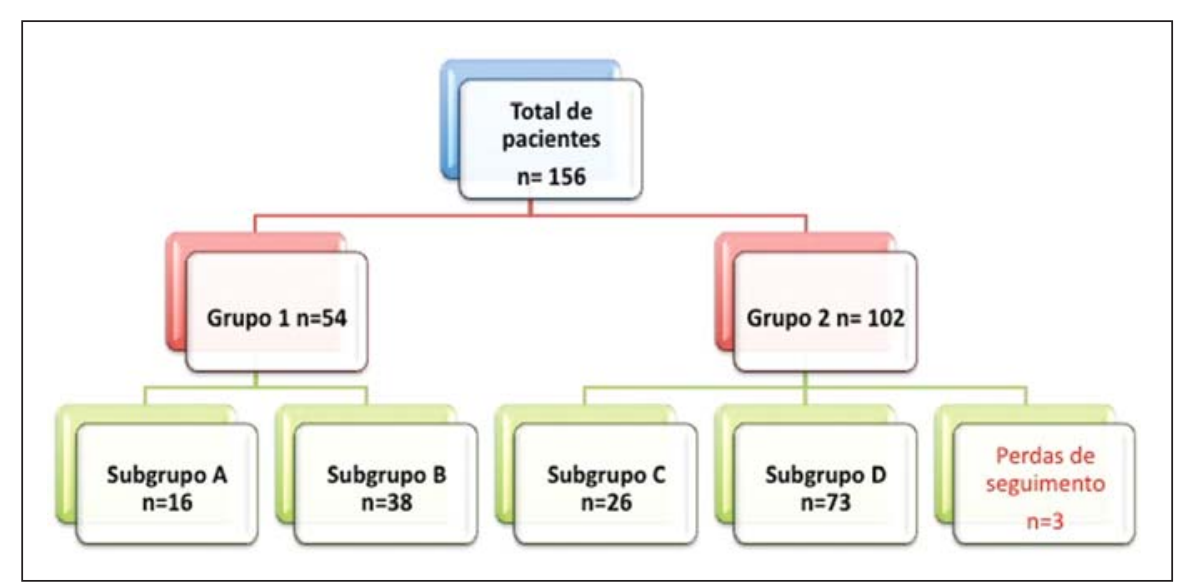

Figure 1. Population distribution chart. 


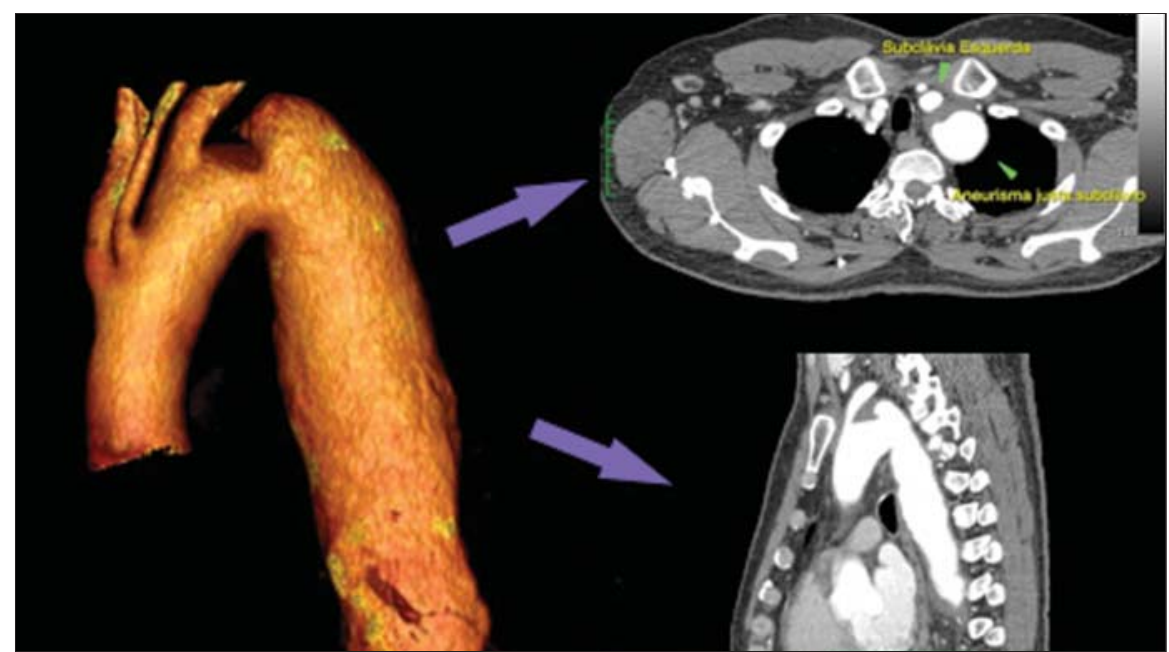

Figure 2. CT angiography with 3D reformatting, axial and sagittal sections. Thoracic juxta-subclavian aneurysm in type 3 aortic arch.

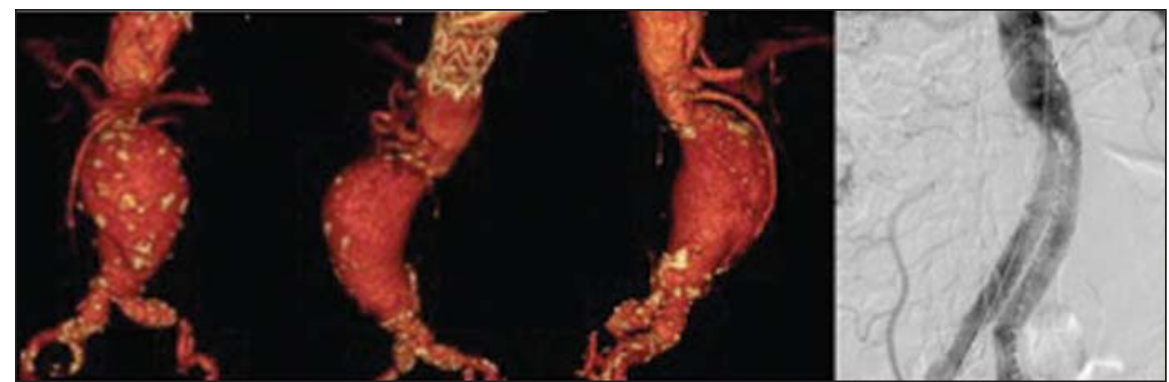

Figure 3. A: CT angiography demonstrating abdominal aortic aneurysm with angulation of proximal aneurysmal neck $>65^{\circ}$ and aortoiliac bifurcation $>90^{\circ}$. B: Endovascular repair with the aortic endoprosthesis.

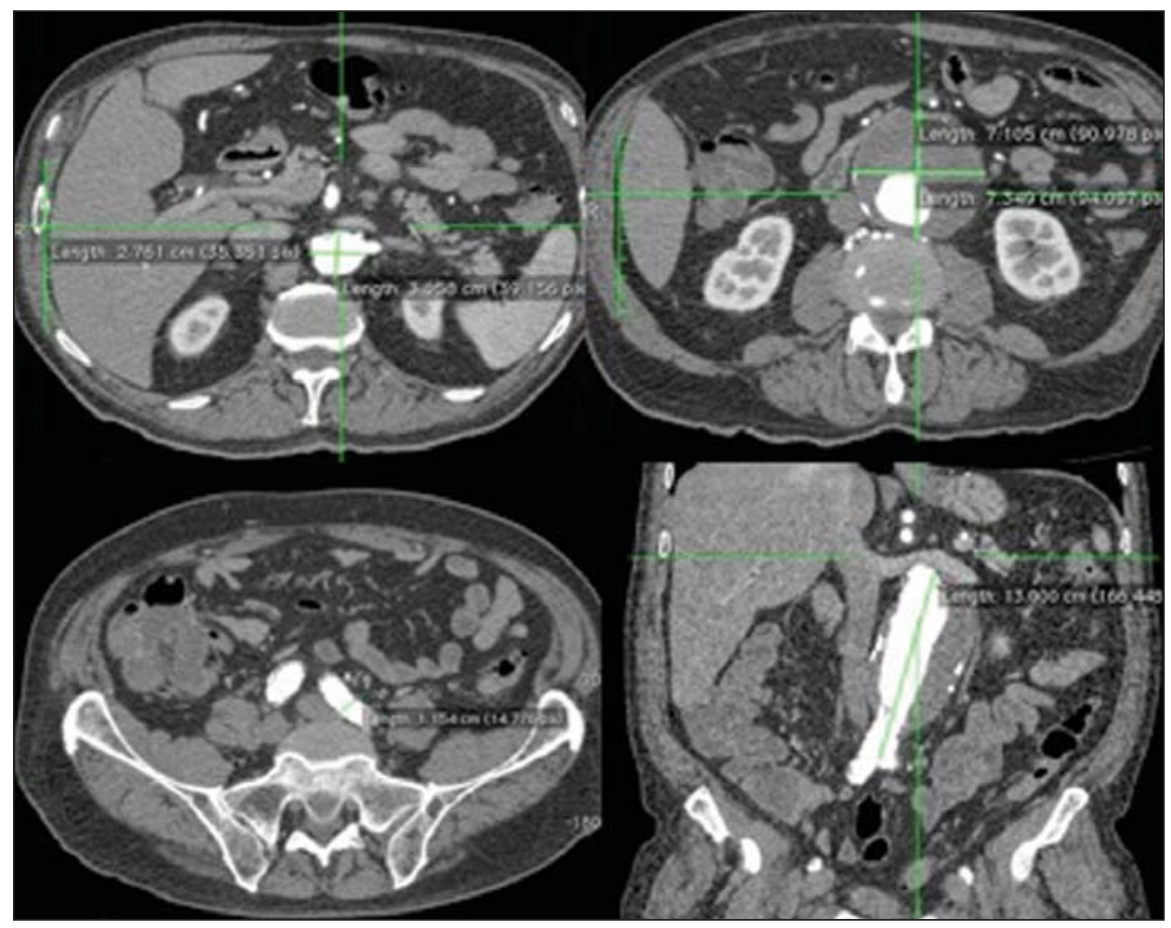

Figure 4. Abdominal aorta CT angiography with multiplanar reconstruction. A: Measurement of the proximal aortic neck. B: Measurement of the left iliac leg. C: Measurement of the greater aortic diameter. D: Measurement of the extent of abdominal aortic aneurysm.

\section{Surgical technique}

All the procedures were performed in a reference center for cardiovascular diseases (Instituto Dante Pazzanese de Cardiologia - São Paulo, SP, Brazil).

The endovascular procedures were performed with the patients under general inhalation anesthesia. The antimicrobial prophylaxis was performed with $1.5 \mathrm{~g}$ cefuroxime at the moment of anesthetic induction. The preferential approach was through the common femoral artery, either uni- or bilaterally, as well as through the left brachial artery, according to the selected type of intervention of endoprosthesis. In cases of impossibility of such approach, the external or common iliac arteries were approached through retroperitoneal access.

The radiographic follow-up was performed with an Artis flat panel apparatus (Siemens; Munich, Germany). Intraoperative arteriography was performed in all the patients (Figure 6). The immediate postoperative management was performed in intensive care unit for all of the cases.

\section{Postoperative follow-up}

The patients were followed-up on an out-patients basis at 15, 30, 180 and 360 days after the procedure. After the first year, the follow-up consultations became annual. CT angiography was performed at the first and at the twelfth months of follow-up. Color Doppler ultrasonography was performed in cases where $\mathrm{CT}$ angiography was contraindicated.

\section{Primary and secondary outcomes}

1 - Technical success: as the objective of releasing the endoprosthesis into the affected vessel was accomplished, either with or without events affecting the favorable evolution of the aortic disease.

2 - Therapeutic success: as the endoprosthesis release occurred without any leakage or other events affecting the favorable evolution of the aortic disease.

3 - Perioperative mortality: quantity of deaths recorded within the first 30 postoperative days.

4-Annual mortality: quantity of deaths occurred within the 12 months of follow-up.

5 - Periprocedural complications: a) intraoperative complications - those occurred in the hemodynamics room, during the intervention; b) perioperative compli- 


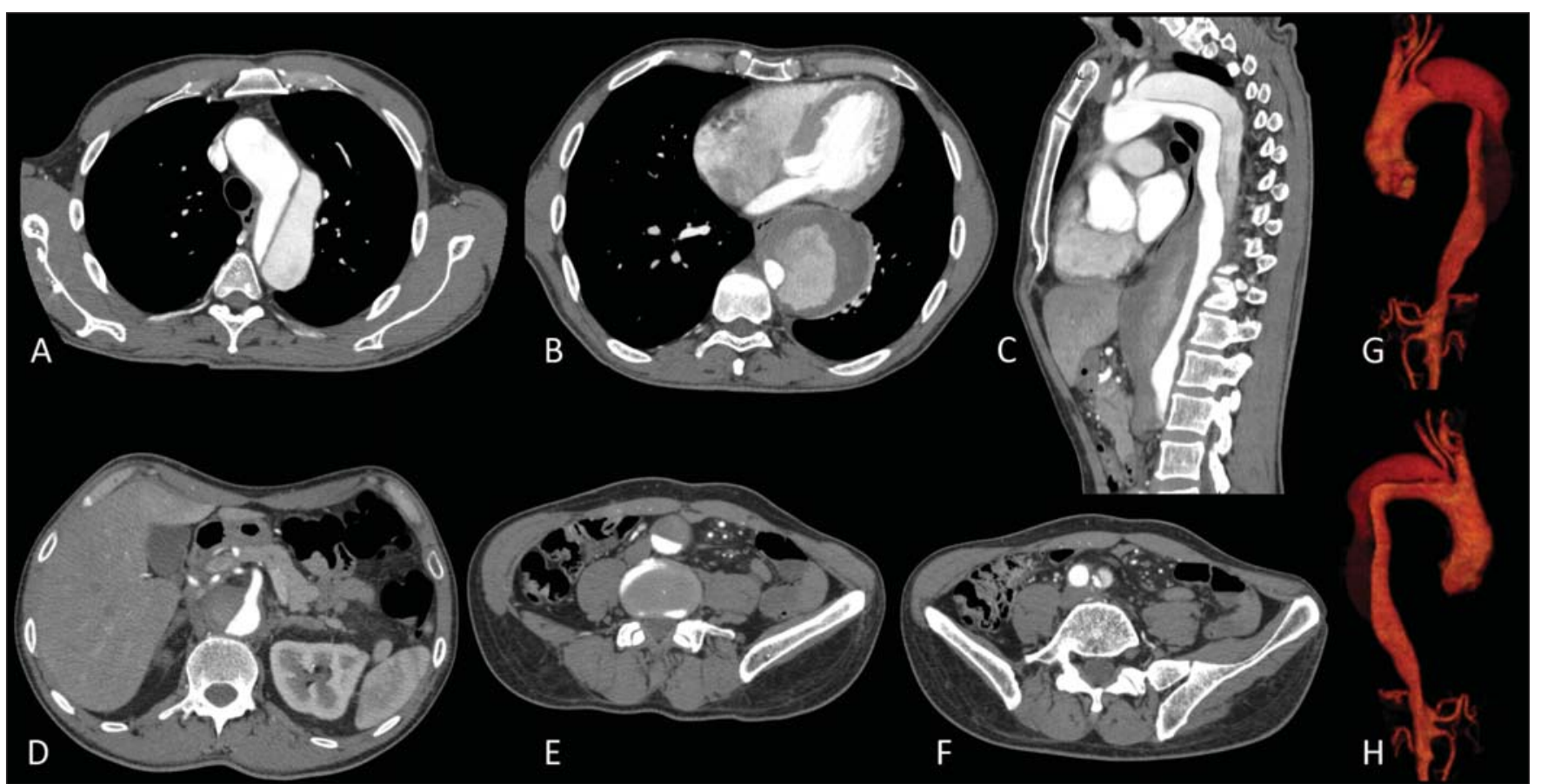

Figure 5. CT angiography with multiplanar and 3D reconstruction. A: Axial section demonstrating the dissection entry point at the level of the left subclavian artery origin. B: Greater diameter of the aorta. C: Sagittal section. D: Superior mesenteric artery originating in the true lumen. E: Involvement of abdominal aorta. F: Dissection at the level of left iliac artery. G: 3D oblique reconstruction, right anterior oblique view.

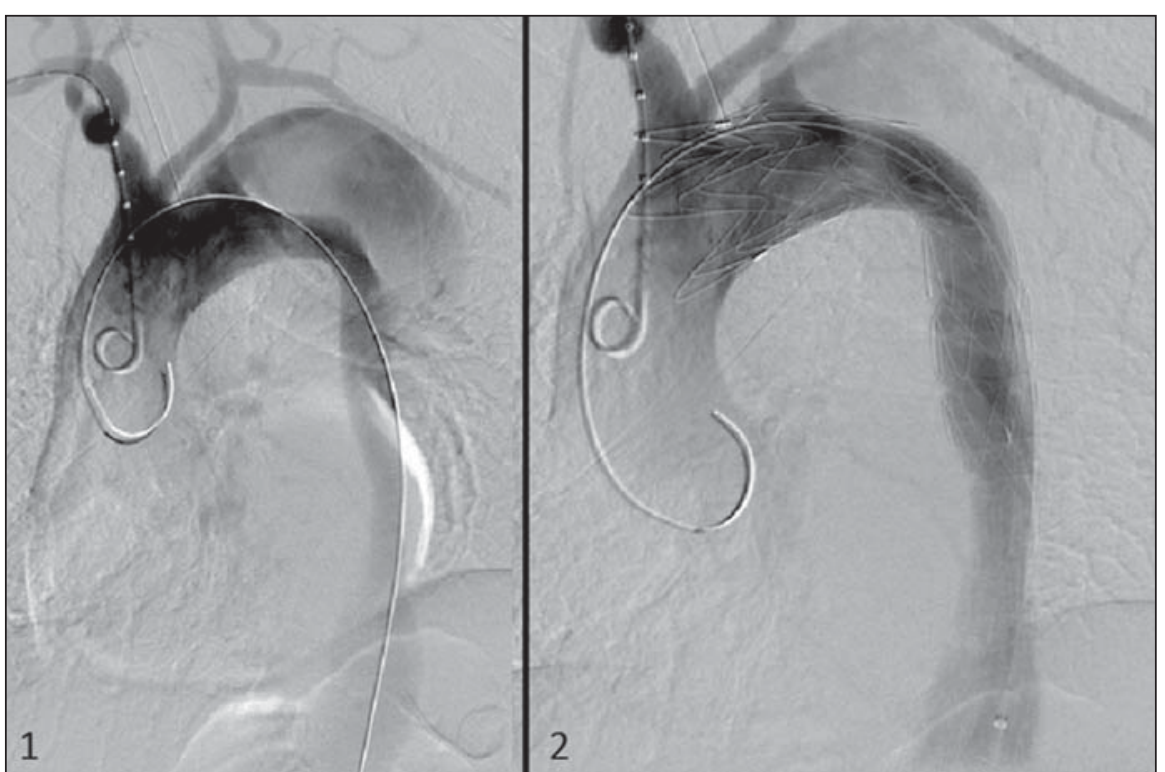

Figure 6. 1: Intraoperative aortography demonstrating Stanford type B aortic dissection in bovine type II aortic arc. 2: Endovascular repair of Stanford type B dissection with presence of type la leakage.

cations - those occurred during hospital stay, out of the hemodynamics room, within 30 days after the intervention.

\section{Definitions}

1 - Initial or primary leakage: originated during the initial procedure, or diagnosed within the first 30 days.
2 - Accuracy in the calculation of the planned endoprosthesis, according to the preoperative measurement, as compared with the utilized endoprosthesis. In cases where the planned endoprosthesis matched the utilized endoprosthesis, the calculation was considered as coincidental. In cases of differences of $>2 \mathrm{~mm}$ in diameter and 20 $\mathrm{mm}$ in length between the planned and the utilized endoprostheses, the calculation was considered as approximate. In cases of greater differences in diameter and length, the calculation was considered as different.

Such criterion, despite still not having been validated in literature, corresponds to the criteria universally utilized in the daily practice of interventional physicians involved in endovascular interventions for aortic diseases.

\section{Statistical analysis}

The exact Fisher test or the chi-squared test was utilized to evaluate the association between the qualitative variables. The Kaplan-Meier curve was utilized for analysis of survival, and the log-rank test was utilized to evaluate the differences between the survival curves. The adopted level of statistical significance corresponded to $5 \%$ $(p<0.05)$

\section{RESULTS}

The present study included 156 patients submitted to endovascular repair of aortic diseases. The G1 included 54 patients -16 of them who underwent $\mathrm{CT}$ angiography and $\mathrm{AG}$ (subgroup A), and 38 underwent 
CT angiography only (subgroup B). The mean age of the patients was $62.4 \pm 8$ years, and $61 \%$ of them were men. The patients were asymptomatic in 24 cases $(44 \%)$. The predominant risk factor was systemic arterial hypertension (100\%), 10 patients $(5.4 \%)$ were diabetic, $28(15.1 \%)$ were smokers, and $21(11.3 \%)$ had dyslipidemia. Obesity (body mass index > 40) was present in 4 patients $(2.1 \%)$ of the study population (Table 1).

Among the comorbidities, the authors observed a high incidence of ischemic cardiopathy (10.8\%). Chronic renal failure and stroke also were present to a lesser degree, respectively $6.4 \%$ and $3.7 \%$. The authors observed a significant percentage of patients with previous history of aortic surgery $(9.7 \%)$ (Tables 1 and 2).

The indications for endovascular repair in such population were distributed as follows: TAA in 22 cases $(11.8 \%)$, previous endoprosthesis leakage in 14 cases $(7,6 \%)$, penetrating aortic ulcer in 2 cases $(1.08 \%)$, pseudoaneurysm in 1 case $(0.5 \%)$, and type $\mathrm{B}$ chronic aortic dissection in 15 cases $(8.1 \%)$.

All the patients were submitted to elective treatments, under general inhalation anesthesia, with selective liquor drainage. Technical success was achieved in all the patients of the subgroup A, while in subgroup B, technical success was achieved in 36 patients $(94.7 \%)$, so in 2 patients the endoprosthesis could not be advanced and placed into the desired location $(p=1)$.

The therapeutic success in the subgroup submitted to preoperative CT angiography $+\mathrm{AG}$ achieved $81 \%$ (13 patients). In such subgroup, three patients presented leakage or events which affected the favorable evolution of the aortic disease (19\%). In the subgroup B, 22 patients had therapeutic success $(58 \%)(p=0.13)$.

The rate of complications in the subgroup A was $12 \%$ (2 patients), and in the subgroup B, $42 \%$ (16 patients) ( $p=0.057$ ). The complications were divided as follows: subgroup $1 A-\mathrm{a}$ ) intraoperative: 1 case of femoral artery injury; b) periprocedural: 1 case of acute renal failure; subgroup $1 B-$ a) intraoperative: 1 case of peripheral embolism, 6 cases of femoral artery lesions, 1 case of left subclavian artery occlusion; b) periprocedural: 2 cases of retroperitoneal

Table 1 Clinical data of the study population $(n=156)$.

\begin{tabular}{lcc}
\hline & \multicolumn{2}{c}{ Value (\%) } \\
\cline { 2 - 3 } Population characteristics & Group 1 $(n=54)$ & Group $2(n=102)$ \\
\hline Mean age (years) & 62.4 & 72.9 \\
Male individuals & 61 & 79 \\
Symptomatic/asymptomatic disease & $56 / 44$ & $24 / 76$ \\
True aneurysm & 11.8 & 88.2 \\
Pseudoaneurysms & 0.5 & - \\
Aortic ulcer & 1.08 & - \\
Type B chronic aortic dissection & 8.1 & - \\
Previous endoprosthesis leakage & 7.6 & 11.8 \\
Elective/emergency surgery & $100 / 0$ & $76 / 24$ \\
Severe obesity (BMI $>$ 40) & 2.1 & 4.9 \\
Smoking history (either active or abstemious for one year) & 15.1 & 22 \\
Diabetes mellitus & 5.4 & 22 \\
Hypertension & 100 & 99 \\
Dyslipidemia & 11.3 & 50 \\
\hline
\end{tabular}

The value corresponds to the number of patients. BMI, body mass index.

Table 2 Comorbidities in the study population $(n=156)$.

\begin{tabular}{lcc}
\hline & \multicolumn{2}{c}{ Value (\%) } \\
\cline { 2 - 3 } Comorbidities & Group 1 $(n=54)$ & Group 2 $(n=102)$ \\
\hline Chronic renal failure & 6.4 & 14.7 \\
Ischemic cardiopathy & 10.8 & 57.8 \\
Dilated cardiopathy & 1 & - \\
Previous aortic surgery & 9.7 & 12.7 \\
Stroke & 3.7 & - \\
\hline
\end{tabular}

The value corresponds to the number of patients.

Table 3 Accuracy in the calculation of endoprostheses according to the number of patients per subgroup.

\begin{tabular}{lcccc}
\hline & \multicolumn{4}{c}{ Number of events (\%) } \\
\cline { 2 - 5 } Measurements & $\begin{array}{c}\text { Subgroup A } \\
(n=16)\end{array}$ & $\begin{array}{c}\text { Subgroup B } \\
(n=38)\end{array}$ & $\begin{array}{c}\text { Subgroup C } \\
(n=26)\end{array}$ & $\begin{array}{c}\text { Subgroup D } \\
(n=73)\end{array}$ \\
\hline Coincidental & $15(87.5)$ & $18(47)$ & $16(62 \%)$ & $38(52)$ \\
Approximate & $1(12.5)$ & $10(26)$ & $4(15 \%)$ & $20(27.7 \%)$ \\
Different & 0 & - & - & 1 \\
\hline
\end{tabular}

hematoma, 2 cases of acute renal failure, 2 cases of paraplegia and 1 death.

The accuracy in the calculation of the prosthesis was higher in the group with TC angiography $+\mathrm{AG}(p=0.065)$. In this group, $87.5 \%$ of the patients presented coincidence between the calculated and the utilized prostheses, and only 1 patient achieved an approximate result. No case of difference between calculated and utilized prosthesis was observed.

In the group submitted to CT angiography only, coincidence between calculated and utilized prostheses was observed in 18 cases $(47 \%)$, and in 10 cases $(26 \%)$ the calculation was approximate (Table 3 ).

No death was observed in the subgroup 1A, while in subgroup 1B 4 deaths were observed during the annual follow-up $(10.5 \%)(p=0.936)$ (Figure 7).

In the G2, 102 patients were included and 3 of them missed the follow-up. In this group, $26(25.4 \%)$ were preoperatively evaluated with CT angiography + AG (subgroup 2C) and 73 TC angiography only (subgroup 2D). The mean age was 72.9 


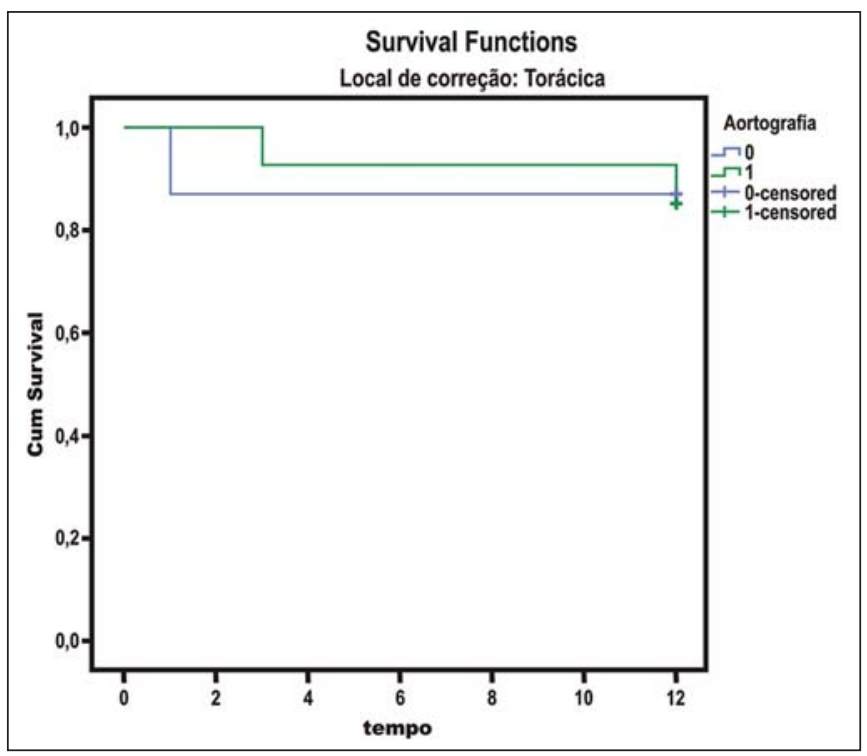

Figure 7. Annual Kaplan-Meier survival curve of group 1. Subgroup 1A in blue: group 1B in green.

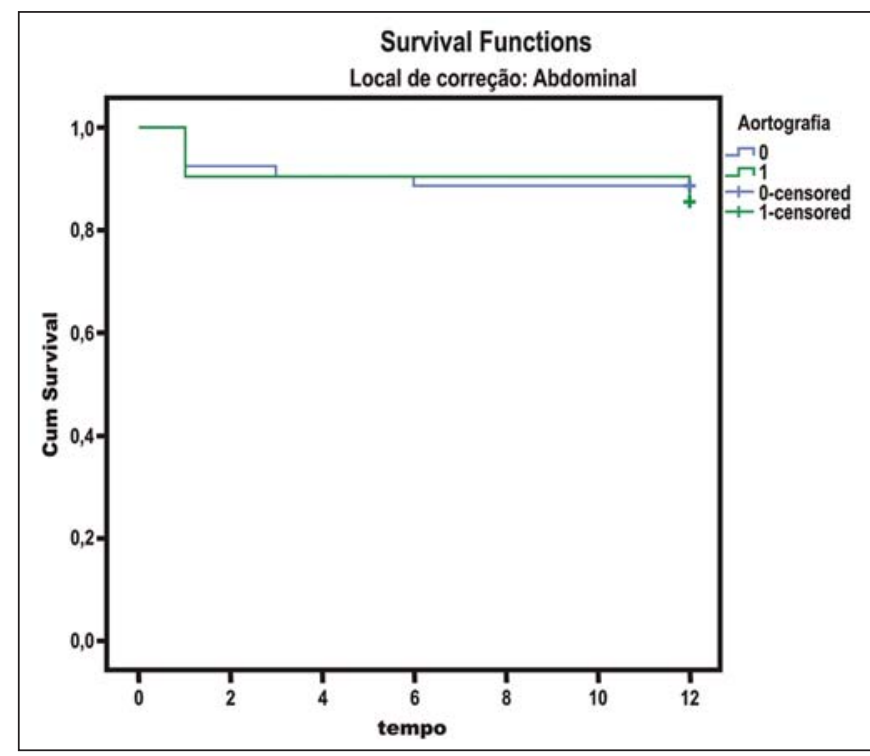

Figure 8. Kaplan-Meier survival curve of group 2. Subgroup $2 \mathrm{C}$ in green, subgroup 2D in blue. years, and $79 \%$ of the patients were men. In $76 \%$ of cases, the patients were asymptomatic. The predominant risk factor was systemic arterial hypertension in 100 patients (99\%), 23 (22\%) were smokers, and 51 patients $(50 \%)$ presented dyslipidemia. Diabetes mellitus was present in 23 cases ( $22 \%$ ), and obesity (body mass index $>40$ ), in 5 patients $(4.9 \%$ ) (Table 1). Among comorbidities, the authors observed a high incidence of ischemic cardiopathy (57.8\%) and chronic renal failure to a lesser degree $(14.7 \%)$. Thirteen patients $(12.7 \%)$ presented with previous history of aortic surgery.

The indications for endovascular repair in this population were distributed as follows: abdominal aortic aneurysm in $88.2 \%$ and leakage in $11.8 \%$. Approximately $24 \%$ of such patients were treated on an emergency basis, because of alarming symptoms. Technical success was achieved in $92.3 \%$ of cases in the subgroup 2C, and in $98.6 \%$ of cases in the subgroup 2D ( $p=$ 0.17 ), while therapeutic success was achieved in $73 \%$ and $98.6 \%$ of cases, respectively $(p=0.79)$.

The rate of complications in the subgroup $2 \mathrm{C}$ was $23 \%$ (6 patients), and in the subgroup 2D was $77 \%$ (56 patients) ( $p=$ 1.0). The complications were distributed as follows: subgroup $2 C-$ a) intraoperative: 3 cases of surgical wound bleeding, 1 case of femoral artery injury, and 1 case of pe- ripheral embolism; subgroup $2 D-$ a) intraoperative complications: 3 cases of surgical wound bleeding, 1 case of renal artery occlusion, 1 case of femoral artery injury, and 1 case of peripheral embolism; b) periprocedural complications: 2 cases of acute renal failure.

Accuracy in the calculation of the endoprosthesis in the subgroup $2 \mathrm{C}$ was coincidental between the calculated and utilized endoprostheses in 16 patients $(62 \%)$, approximate in 4 patients $(15 \%)$, and in 6 patients $(23 \%)$ such evaluation could not be performed. In the subgroup 2D, coincidence between the calculated and utilized prostheses was observed in 38 patients $(52 \%)$, approximation in 20 patients $(27.7 \%)$, and difference in 1 patient. In 14 patients, such evaluation could not be performed ( $p=0.46$ ) (Table 3).

The annual mortality rate in the subgroup 2C was $14.3 \%$, and in the subgroup 2D, $11.3 \%$ (Figure 8 ). The annual global survival in the G1 was $86.7 \%$, and in the $\mathrm{G} 2,87.8 \%$.

\section{DISCUSSION}

Preoperative CT angiography, either in association or not with conventional arteriography, represents the standard in the investigation of aortic diseases ${ }^{(4,11)}$. The present study has evaluated the utilization of preoperative aortography as a useful tool for the planning of an appropriate treatment. In the present study sample, the number of preoperative AG studies was higher in the G1 as compared with the G2 $(29.6 \%$ versus $25.4 \%$ ). The authors observed that the percentage of coincidental measurements in the cases where thoracic aortography was performed corresponded to $87.5 \%$ versus $47 \%$ in the cases where such imaging study was not performed. The number of approximate calculations was lower in the thoracic population with $\mathrm{AG}$ (6.3\% versus $26 \%, p=0,065)$. Maybe, a larger study sample could increase the level of statistical significance observed in the present study.

The angiographic investigation of the aortic arch, descending thoracic aorta, and abdominal aorta demonstrates alterations such as stenosis, dilatation, ulcerations and anatomical variations, but this method is associated with a higher morbidity and lower images definition to identify presence of calcifications, tortuosity and ostial stenosis as compared with CT angiography. This is due to the fact that AG is a biplanar study of the arterial lumen, while CT angiography is a 3D study ${ }^{(\mathbf{1 3 , 1 4})}$. The success of the endovascular repair depends on the anatomical and morphological evaluation of the aortic walls (presence of calcifications and thrombi), as well as on the correct measurements of the diameter and length of the proximal and distal landing zones. 
The rate of coincidence in the calculation of the endoprosthesis was higher in the G1 than in the G2. The latter presented a higher rate of approximate calculations, demonstrating that, in the investigation of thoracic aortic diseases, pre- or intraoperative arteriography may be a useful resource for a better surgical planning. Therefore, as the proximal and distal necks of an aneurysm are assessed, it is observed that CT is the best method for measuring their diameter, considering that both digital subtraction angiography and magnetic resonance angiography rely on the contrast column to identify the diameter, underestimating its actual value. On its turn, AG with a marked catheter is more accurate in the measurement of the neck length, aneurysmal extent, and in the determination of the best location for the endoprosthesis release, aiming at the occlusion of the entry ostium in dissections as well as in cases of endoprosthesis release proximal to branches of the supra-aortic trunk. In abdominal aortic diseases, axial sections of CT angiography are not appropriate to evaluate iliac segments, since such vessels present inclinations both in the coronal and sagittal planes. Images reformatting and display in the coronal, sagittal and three-dimensional allow a better evaluation. The quality of such images reconstruction depends upon expensive post-processing techniques ${ }^{(\mathbf{1 5 , 1 6 )}}$, for this reason arteriography is more useful in the calculation and planning of extensions in the contra- or ipsilateral legs, due to tortuosities frequently observed in such cases.

In both $\mathrm{G} 1$ and $\mathrm{G} 2$, variables such as technical success, therapeutic success and mortality did not demonstrate any statistically relevant marker which might suggest the association of CT angiography + AG presents some advantage as compared with CT angiography only.

As regards complications, in $\mathrm{G} 2$, the authors observed two patients with iliacofemoral occlusion, and only one of them underwent preoperative AG. On the other hand, in G1, 7 patients presented iliacofemoral injuries and, among them 6 had not been submitted to preoperative AG. Additionally, the authors observed that in both groups the patients preoperatively prepared with the two imaging methods presented a low incidence of complications. In G1, the sample size limited the statistical significance $(p=0.057)$.

It is important to highlight that the longer the pathway of the endoprosthesis placement system, the greater the anatomical obstacles to be overcome and, therefore the greater the likelihood of complications. The pathways of the endoprosthesis placement systems were longer in the G1 as compared with the G2, and should overcome the frequent thoracic and iliac anatomical distortions, as well as the greater tortuosity of the aortic arch.

Digital AG remains as the standard in the investigation of parietal branches such as, for example, the bronchial arteries, intercostal arteries, and those arteries supplying the spinal cord $^{(\mathbf{1 7 - 2 0 )}}$. This has implications for the rate of complications. In G1, the authors observed two cases of permanent paraplegia where the patients had been preoperatively evaluated with CT angiography only.

With the arrival of new imaging technologies which offer a better accuracy in endovascular therapy plannings, intravascular ultrasonography has been utilized in association with AG. Intravascular ultrasonography is an excellent method to evaluate the vessel walls. An intensely calcified wall is a predictor of leakages, while the attachment of the prosthesis to parietal thrombi may give a false idea of fixation, predisposing to graft migration with consequential later leakage. In spite of the fact that intravascular ultrasonography does not demonstrate decreased leakage in aortic endoprostheses repair, this method can be useful in the evaluation of more complex landing zones, either because of the tortuous anatomy or because of the necessity of accuracy in the release of devices to preserve the visceral branches ${ }^{(\mathbf{2 1})}$.

Finally, the real time evaluation of leakages with AG allows the observation of the volume of loss of leakage, including in type IV leakages, which are indirectly suggested by CT, by the enlargement of the aneurysmal sac without the presence of the other types of leakages, leading to the adoption of therapeutic measures at the moment of images acquisition.

\section{Study limitations}

The limitations were connected with the following factors: number of patients evalu- ated, the retrospective nature of the study, the non randomized comparison between the groups, and the utilization of criteria still to be validated in the literature to evaluate the measurements of the endoprostheses. Such factors lead to limitation of the conclusions and of the comparison with more comprehensive studies.

\section{CONCLUSIONS}

In the present study, the utilization of preoperative aortography in the evaluation of abdominal aortic diseases has not influenced the selection of the preoperatively calculated and the actually utilized endoprosthesis, as well as did not modified the patients' outcomes.

In the group of patients with thoracic aortic diseases, preoperative arteriography resulted in a greater coincidence between the preoperatively calculated and the utilized prosthesis, but, also, the outcomes did not change.

Therefore, the authors conclude that the diagnostic angiographic study should be reserved for the cases where CT angiography cannot provide all the reliable information required for the planning of a therapeutic intervention, or in the presence of anatomic adversities to be overcome in order to achieve the treatment objectives.

\section{REFERENCES}

1. Met R, Bipat S, Legemate DA, et al. Diagnostic performance of computed tomography angiography in peripheral arterial disease: a systematic review and meta-analysis. JAMA. 2009;301:41524

2. Albuquerque LC, Palma JH, Braile DM, et al. Diretrizes para a cirurgia das doenças da aorta. Arq Bras Cardiol. 2004;82(Supl V):35-50.

3. Nyman R, Eriksson MO. The future of imaging in the management of abdominal aortic aneurysm. Scand J Surg. 2008;97:110-5.

4. Turina MI, Shennib H, Dunning J, et al; EACTS/ ESCVS Committee. EACTS/ESCVS best practice guidelines for reporting treatment results in the thoracic aorta. Eur J Cardiothorac Surg. 2009; 35:927-30

5. Svensson LG, Kouchoukos NT, Miller DC, et al; Society of Thoracic Surgeons Endovascular Surgery Task Force. Expert consensus document on the treatment of descending thoracic aortic disease using endovascular stent grafts. Ann Thorac Surg. 2008;85(1 Supp):S1-41.

6. Albrecht T, Foert E, Holtkamp R, et al. 16-MDCT angiography of aortoiliac and lower extremity arteries: comparison with digital subtraction angiography. AJR Am J Roentgenol. 2007;189:70211 
7. Juvonen T, Ergin MA, Galla JD, et al. Risk factors for rupture of chronic type B dissections. J Thorac Cardiovasc Surg. 1999;117:776-86.

8. Akutsu K, Nejima J, Kiuchi K, et al. Effects of the patent phase lumen on the long-term outcome of type B acute aortic dissection. Eur J Cardiothorac Surg. 2004;26:359-66.

9. Nienaber CA, von Kodolitsch Y, Petersen B, et al. Intramural hemorrhage of the thoracic aorta: diagnostic and therapeutic implications. Circulation. 1995;92:1465-72.

10. Nienaber CA, Rousseau H, Eggebrecht H, et al. Randomized comparison of strategies for type B aortic dissection: INvestigation of STEnt Grafts in Aortic Dissection (INSTEAD) trial. Circulation. 2009; 120;2519-28.

11. Chaikof EL, Brewster DC, Dalman RL, et al. The care of patients with an abdominal aortic aneurysm: the Society for Vascular Surgery practice guidelines. J Vasc Surg. 2009;50(4 Suppl):S2-49.

12. Leurs LJ, Bell R, Degrieck Y, et al.; EUROSTAR; UK Thoracic Endograft Registry collaborators.
Endovascular treatment of thoracic aortic diseases: combined experience from the EUROSTAR and United Kingdom Thoracic Endograft registries. J Vasc Surg. 2004;40:670-80.

13. Almeida MO, Baroni RH, Aun R, et al. Próteses endovasculares em aneurisma da aorta: avaliação pela angiotomografia. Rev Imagem. 2004;26 133-9.

14. Rodrigues S, Abrantes AF, Ribeiro LP, et al. Estudo da dose nos exames de tomografia computadorizada abdominal em um equipamento de 6 cortes. Radiol Bras. 2012;45:326-33.

15. Carroccio A, Faries PL, Morrissey NJ, et al. Predicting iliac limb occlusions after bifurcated aortic stent grafting: anatomic and device-related causes. J Vasc Surg. 2002;36:679-84.

16. Novero ER, Metzger PB, Angelieri FMR, et al Correção endovascular do aneurisma da aorta abdominal: análise dos resultados de único centro. Radiol Bras. 2012;45:1-6.

17. Cinà CS, Abouzahr L, Arena GO, et al. Cerebrospinal fluid drainage to prevent paraplegia during thoracic and thoracoabominal aortic aneurysm surgery: a systemic review and meta-analysis. J Vasc Surg. 2004;40:36-44.

18. Biglioli P, Roberto M, Cannata A, et al. Upper and lower spinal cord blood supply: the continuity of the anterior spinal artery and the relevance of the lumbar arteries. J Thorac Cardiovasc Surg. 2004; 127:1188-92.

19. Novero ER, Metzger PB, Obregon J, et al. Tratamento endovascular das doenças da aorta torácica: análise dos resultados de um centro. Radiol Bras. 2012;45:251-8.

20. Metzger PB, Fontes DCC, Novero ER, et al. Tratamento endovascular da dissecção crônica de aorta tipo B complicada. Rev Bras Cardiol Invasiva. 2012;20:184-90.

21. Arko FR, Murphy EH, Davis CM 3rd, et al. Dynamic geometry and wall thickness of the aortic neck of abdominal aortic aneurysms with intravasculat ultrasonography. J Vasc Surg. 2007; 46:891-7. 